\title{
Interventional Study
}

National Cancer Institute

\section{Source}

National Cancer Institute. Interventional Study. NCI Thesaurus. Code C98388.

Studies in which individuals are assigned by an investig ator based on a protocol to receive specific interventions. Subjects may receive diagnostic, therapeutic or other types of interventions. The assignment of the intervention may or may not be random. The individuals are then followed and biomedical and/or health outcomes are assessed. 